\title{
BARRIER-FREE PARK IN PRIZREN - VISIONING WORKSHOP INVOLVING PERSONS WITH DISABILITY AND THE ELDERLY
}

\author{
Rozafa BASHA \\ Faculty of Civil Engineering and Architecture, University of Prishtina 'Hasan Prishtina' \\ Kodra e Diellit, p.n. 10000, Prishtinë, Republic of Kosovo \\ e-mail: rozafa.basha@uni-pr.edu
}

Received 5 December 2017; accepted 12 February 2018

\begin{abstract}
Though problems related to physical accessibility of the built environment are quite complex, this paper chooses to discuss the case study of a Visioning Workshop for the City Park of Prizren as a model of participatory workshop with the involvement of persons with disability and the elderly. The main aim of the paper is to discuss the participatory design workshop, which objective was finding solutions for elimination of physical barriers in the park and providing programs that would increase its vitality. Participatory design workshop in this case is presented as a methodology for gathering information, establishing design criteria and programmatic requirements with the involvement of the community of persons with disability.
\end{abstract}

Keywords: Barrier-free park, Community involvement, Visioning workshop, Persons with disabilities

\section{Introduction}

Eliminating architectural barriers in the city to enable the free movement of people with impaired mobility is the cornerstone of equality and democracy in a city. Everyone has the right to live and use the city, and to enjoy the benefits the city can offer. Cities that are accessible for all people, regardless of gender, ability, age, ethnicity, sexual orientation and financial opportunity are called inclusive cities.

There are many groups and communities that due to various physical, cultural and institutional barriers are marginalized from taking part in daily activities in the city. In Kosovo, this is quite evident as cities are planned and constructed without any regard to the diversity of demands of all members of the community. By a simple observation, if 
the structure of population seen daily in the streets of Kosovo cities is compared with the structure of population in any other European city, it will be noticed that there are less People with Disabilities (PwD) present in public spaces. This does not indicate a negligible community in Kosovar population's composition. A large number of physical barriers in the city, in the residential buildings, public facilities, local administration, etc. make the independent movement impossible for people with impaired mobility. On the other hand, the so called institutional barriers, the incomplete legal framework on barrier-free environments, lack of mechanisms to implement the existing legislation are among many elements contributing greatly to limitations to independent movement and social inclusion of marginalized communities, thus making Kosovo cities exclusionary.

In a broader view, an important contributor to making the cities of Kosovo exclusionary are the problems related to planning activities and decision-making for the city, especially for public facilities and public space. An important approach that can have a major impact in making the city friendlier to everyone, including people with disabilities, is making the city in cooperation with all resident communities. Cooperation in making the city implies that in all discussions about city plans the community should be involved alongside experts, planners, architects, politicians and other administrative officials. Only in this way can a greater representation of the basic needs of communities in city planning be ensured.

Though the problems related to accessibility of public spaces in Kosovar cities are multifaceted and quite complex, this paper chooses to discuss and promote the participatory design approach, which as it is stated by Fenster, is the right of inhabitants to take a central role in decision-making processes surrounding the production of urban space at any scale [1, pp. 65] and as indicated by Portschy, it is a mutual learning process, in which community, design practitioners, municipalities and authorities would need to acquire the necessary skill set and pursue sufficient openness [2]. By discussing the case study of Visioning Workshop for the City Park of Prizren, this paper also aims to introduce the participatory design workshops as a methodology for facilitating gathering information, establishing design criteria, programmatic requirements, etc. [2]. The participating community in the discussed workshop was composed of a significant group of people with various disabilities and partly of elderly citizens, youth and ablebodied working age women and men. Finally, this paper aims to promote a model of design workshop where community needs of the elderly and people with disabilities are put at the forefront, and not limited to merely providing physical access to the park, but ensuring that their voices are heard fully and their leisure time and recreation needs are taken into equal consideration with those of other citizens.

\section{Background of the study}

\subsection{The question of the accessibility of built environment in the cities of Kosovo}

The built environment in Kosovo towns and villages continues to be partly or entirely inaccessible for the community of persons with disability; and although the legal framework to some extent ensures non-discrimination and the removal of barriers to guarantee full participation in society, cultural prejudices and current mindset 
resulting from lack of information and lack of legal mechanisms that would lead to full implementation of applicable regulations for improving accessibility and integration in the society, makes this community one of the most marginalized ones in Kosovar society.

Based on the challenging situation people with disabilities face in Kosovo, in recent years a number of awareness campaigns and actions seeking governmental consideration with respect to the inaccessible built environment were undertaken. Thus, in 2007 the newly approved Kosovar building code was supplemented by administrative instruction (Administrative Instruction 33/2007) [3] regulating buildings' accessibility for disabled persons. Though 10 years have passed, this regulation has not influenced a lot the construction practice in public and private sector in Kosovo.

The existing stock of public buildings has seen mandatory improvements by providing minimal accessibility, but in the majority of cases these technical interventions have not improved much the accessibility of the buildings whatsoever. Many of them, by ways of fulfilling the technical requirement, designed and executed by incompetent companies and lacking inspection from the municipality, ended up with access ramps with insurmountable incline, unequipped accessible toilets, obstacles in the floors, etc., among many other problems. The case of public space accessibility is far more complicated as many problems, apart from the incompetent realization, bad design, lack of planning and faulty supervision of public works, stem from bad management of public spaces in the cities. Henceforth, while technical provisions provide regulations for sidewalks, crossings, curb dimensioning, bad municipal management of public spaces has resulted in having the majority of sidewalks narrowed or completely blocked by parked cars or by private shop owners. Alongside bad municipal management, previous investigations in 2015 concluded that among principal accessibility problems in public spaces in Prishtina and Prizren, despite that the existing regulation provide ready-made solutions remain the incompetent adaptations and improvement works. Adaptations tend to complicate, extend and reroute the path of the disabled, thus contributing to their invisibility in the public realm [4].

\subsection{The practice of community involvement in planning in Kosovo}

On the top of actual problems of the built environment, there are problems related to planning and decision-making for the city. An important approach that can have a major impact in making the city friendlier to everyone, including people with disabilities, is making the city in cooperation with all the resident communities. Co-operation in making the city implies that in all discussions about city plans the community should be involved alongside experts, planners, architects, politicians and other administrative officials.

In Kosovo, based on the existing Law for Spatial Planning [5] community involvement in the planning process is regulated by mandatory provisions that determine the number of public discussions of projects and plans that need to be performed before the plans are validated. However, public discussions, in the way they are held in Kosovo, are not at all a form of community-based co-operation in city planning. They are usually held in plenary sessions with a limited audience, since the forms of public notification used by the local administration are not very effective. At 
plenary sessions, attendees (with the absolute majority of able-bodied working age men) are expected to hear few isolated commentaries on the final stages of the plans, which are typically presented in a medium not very comprehensive to them. Consequently, the public presents no specific request or need of the resident community of the planned area or any substantial comment about the plan. With this process completed, the plans, once getting the green light of having held a public discussion, go to the assembly for approval. And as a consequence of this flawed planning process, and lack of communication with the community (in particular with the most marginalized ones), neighborhoods and the entire built environment remain problematic and exclusionary for communities with limited mobility.

\section{Literature review}

Accessibility is a constantly evolving concept, and together with usability, it is a quality requirement for every service. In addition to responding appropriately to the specific needs of PwD community, it adds comfort and security to everyone. Physical access creates a vital contribution in increasing the social participation of people with disabilities [6]. An accessible public space could act as a ground for elevated democracy in the city and a more tolerant society. In this respect Carr et al. indicate that seeing different people respond similarly to the same setting results in creating temporary bonds between them [7, pp. 344]. On the other hand, providing accessibility to a public green, as it is the case study of the workshop that is discussed here, among many other things, it has a positive impact on social and psychological aspects of citizens [8]. Urban public green is an important factor in sustainable development of cities; due to ecological and social benefits it provides [9]. Hence, making urban environments accessible is a big step towards creating a cohesive, sustainable society that integrates all its members for strong relations and equal participation. The concerns of disability and access, women and planning, crime and design, environmentalism and community development are all found within the framework of new urban design agenda [10].

Concerning the accessibility of public spaces Carr at al. assert that the ability to enter public spaces is basic to their use. They suggest three major interacting components of conceptualization of access, which are physical, visual and symbolic access and which represent the so called 'rights to access' [7, pp. 137].

This paper focuses in promoting the participatory planning as one of the means of providing solutions to accessibility problems of marginalized communities. The participatory planning methodology is defined by Portschy as the one that integrates users of the built environment into conceptualizing, designing, building and maintenance processes, etc. He further indicates that while amplifying user satisfaction participatory planning encourages the sense of ownership and addresses environmental inequities [11].

Public participation in planning according to Purcell 'is the right of inhabitants' to be at the core of decision-making processes regarding the production of urban spaces at any scale [12]. The participation of users in the production of a design (the appearance and handling of a product and/or service) is named participatory design [13]. Community involvement in designing a neighborhood or a city according to Nan Ellin 
exposes 'local gifts' and helps discover an 'expanded field of genius loci.' She continues that 'beginning with tabula plena' the process enables disclosure of meaningful expressions because of the empowering and trust building effect the whole process has in the participants when they share what they value the most while evolving with the facilitators and co-creating proposals of shared value [14, pp. 13-14].

Participatory approach in planning and designing the built environment is the core concept around, which the notion of inclusive planning evolves. Inclusive planning processes and decision-making for the city, translates the vision of inclusive city into a physical environment that provides possibilities for people of a wider spectrum of economic and social background to participate and get the value from the project. Imrie states that inclusive design has much in common with Sommer's [15, pp. 18] conception of social design or a process, which seeks to place building users at the fulcrum of design processes rather than at their margins. On the other hand, Binder et al. state that participatory design is a democratic design experiment that among other things entails balancing the focus of materiality and objects with that of humans and sociality [16].

\section{Case study, visioning workshop city park of Prizren}

As it is pointed out above, by ways of discussing the Visioning Workshop for the City Park of Prizren [17] this paper seeks to propose a model of participatory design workshop as a methodology for facilitating gathering information, establishing design criteria and programmatic requirements with the involvement of community of persons with disability in projects. This workshop sought to provide solutions for elimination of physical barriers that hinder the movement of communities with impaired mobility. These solutions include spatial and physical interventions and activities and programs that would ensure that all park recreational areas are accessible to adults, young people and children, the elderly and people with disabilities. The workshop also sought to provide a model of community planning and design with the involvement of people with disabilities and the elderly. Concentrating in the teamwork with people with impaired mobility, the methodology of this participatory workshop aims as Jos Boys indicates to have a broader understanding of the user of the public space by taking 'notice of diverse disabled narratives' [18, pp. 23] among other things. This is particularly important as the resulting designs aim to provide a solution for an overall improvement of the accessibility in the park.

The main reason to address this park's problems within a vision for a greater vibrancy and access for all is a great number of physical barriers for the PwD community. A number of obstacles that PwD face in the park are partly due to topography, while on the other hand the design of existing infrastructure, playground areas and fitness equipment are not fit to be used by everyone.

\subsection{Methodology of work}

For the purpose of accomplishing the work with the community during the visioning workshop, the following materials were made available: 
- Maps of the site location - Prizren's wider and narrow context (Fig. 1);

- Photographs of some physical barriers identified during the team's preliminary visit to the park;

- A portfolio of examples - international examples of different solutions for the elimination of architectural barriers. Examples of recreation and sports equipment usable by all people and children regardless of ability;

- A survey questionnaire.

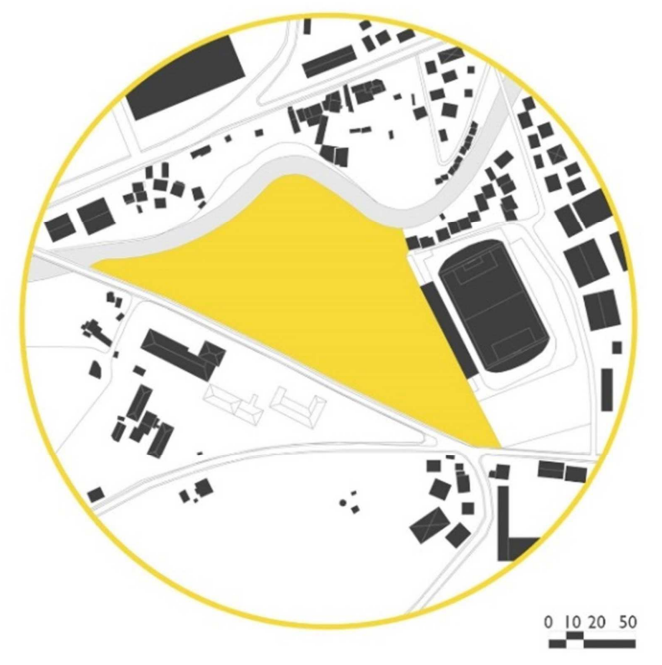

Fig. 1. Site location of the City Park of Prizren (Illustration (C) R.Basha)

A note should be taken here regarding tools of communication with the visually impaired participants. Due to reserved preparation time for the workshop and limited possibilities in Kosovo for producing materials in Braille inscription, the survey and discussion of examples with this community was conducted orally.

Visioning Workshop for the City Park of Prizren took place in August and September 2016. The stages of preparation and realization of this workshop are presented below:

The first stage. Through a desk research, literature review and the review of the regulation of Kosovo and European best practices a framework of methodology was established and a portfolio of best practices that informed the facilitators work with the community was done. An analysis of the location in the city of Prizren was done using maps. This processes were complemented by two daily visits to the city park by the research team (Fig. 2a) Preliminary analysis of access problems for PwD within the park was carried out through another visit to the park done by the project team in the company of two members of the community of PwD (Fig. 2b). Concrete problems of physical accessibility for PwD were identified in this phase. With this situation 
evidenced on the field, maps and pictures were prepared as a basic document for the implementation of the visioning workshop.

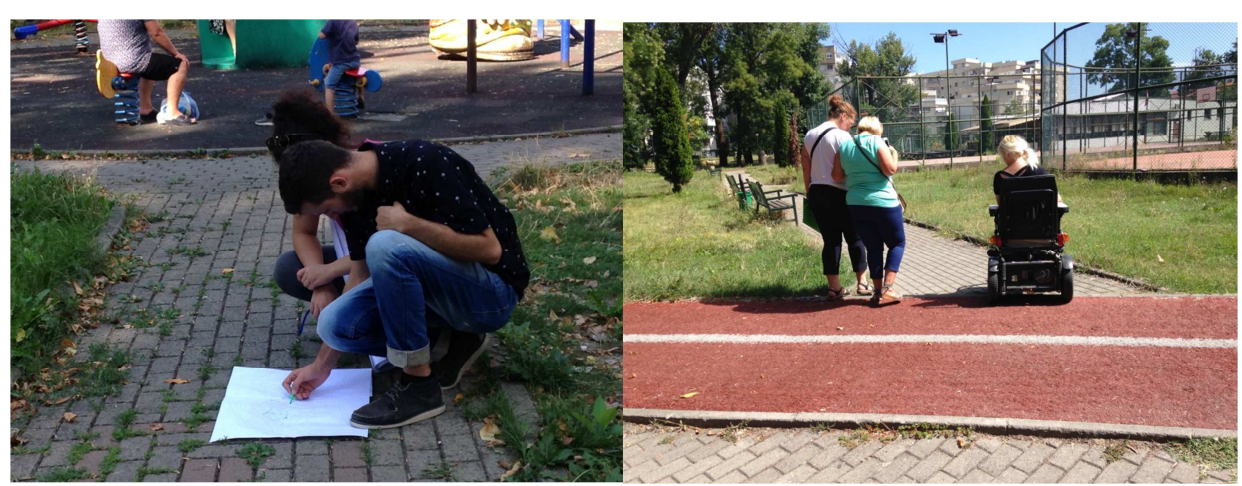

a)

b)

Fig. 2. Analysis of accessibility problems in the park (photo: R. Basha)

The second stage - Workshop realization. The participating community was composed of 22 people of which 13 were PwD and 9 were able bodied women and men of various age. The group of PwD consisted of mechanical and electrical wheelchair users and people with impaired vision. In terms of gender the participating community consisted of 10 women and 12 men. The workshop was facilitated by an architect and a student of architecture.

This stage consisted of following steps:

Free discussion. The discussion highlighted that many institutions in Prizren remain difficult to access and that the city's problematic sidewalks and inaccessible public transport make the movement in the city very challenging for PwD.

Questionnaire survey. The survey was designed in a comprehensible manner and it helped indicate some of the key accessibility problems for PwD in the park. This tool helped the project team and the participants to understand the reasons and motives for not visiting the park, but it also made it possible to highlight the qualities of the park.

Group work. Participants divided into 3 mixed groups and guided by the facilitators identified problematic sites and areas (Fig. 3a). As was indicated earlier, the participatory design approach is a mutual learning process [2], and at the same time it has an empowering and trust building effect in the participants [14, pp. 13]. Hence alongside facilitators' expert insights on the matter participants were asked to bring forward their own examples of good practices of accessible public spaces. The problems and proposals were pointed out in scaled maps of the park (Fig. 3b). Discussions aimed at getting as much as possible feedback regarding accessibility not from the mere perspective of park's internal facilities and infrastructure but looking at a wider scale how easy it was to reach the park from remote parts of the city. 
The third stage. This stage included production of design proposal and vision images taking into consideration proposals set forth by participants of the workshop. The team outlined a draft design proposal and produced several vision images for the accessible City Park of Prizren, which were presented to the workshop participating community in another session held a month later. With comments from the participants the project team finalized the production of design proposals and thus completed the visioning project for the city park. At this stage a workshop report presenting the design proposal and vision images was produced as well [17].

As the park is a public city asset, the city management due to lack of resources, periodically opens calls for private companies to apply for the management of park. The visioning workshop for the City Park was an effort taken by urban activists and civil society organizations to improve general accessibility in the city. The produced vision and design concepts discussed here were delivered to the municipality of Prizren's Directorate of Public Facilities [19] with the intention to serve as basic criteria of the required regeneration of the park by the bid-winning company.

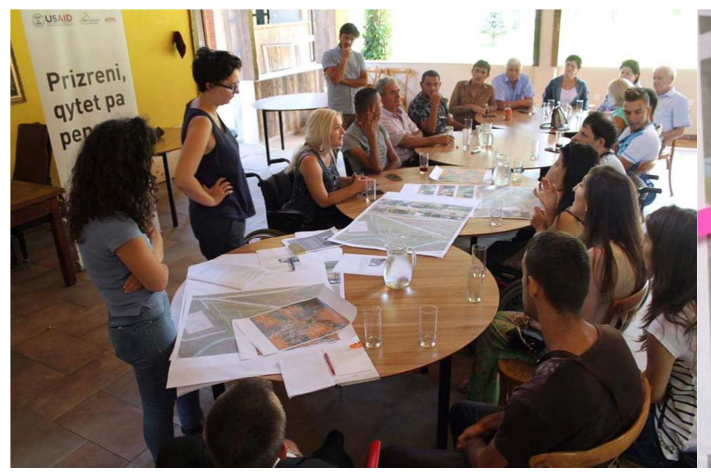

a)

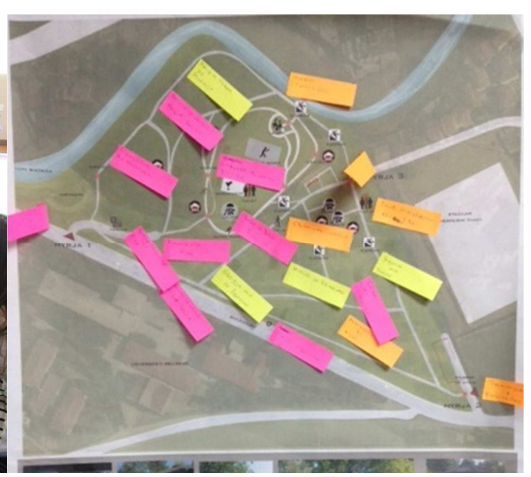

b)

Fig. 3. Group work during the workshop (photo: NGO EC Ma Ndryshe, OPDMK \& R. Basha)

\subsection{Discussion of findings from the visionary workshop}

The questionnaire survey summarized a number of problems for which the park is underutilized. Among the major problems are the inability to access the park due to inaccessible buses and city sidewalks. This makes the park unattractive to many people living in distant neighborhoods regardless of their age, ability or gender.

The park lacks programming and functions, while low quality recreation equipment and neglected sports infrastructure make the park unpleasant area as well. On top of this, due to improper management of the park, the vegetation is not cared properly, the furniture is vandalized and the space is littered heavily. These factors were seen as contributors to the unsafe perception of the park. Hence, it is heavily avoided, in particular by women and older citizens, and this, on the other hand makes the park a favorable site for petty crime youth. The respondents highlighted that the feeling of insecurity is reinforced by the lack of evening lighting as well. 
The survey also highlighted that the reasons behind the disabled community's hesitation to visit the park are many physical barriers within the park, such as trails with insurmountable slope, damaged path surfaces, lack of tactile surfaces to guide the movement of the visually impaired persons, missing toilets for people with disabilities, lack of inclusive fitness and playground equipment for adults and for children with disability, etc.

\section{Workshop output data}

The resulting vision statement derived from Visioning Workshop for the City Park of Prizren is as follows: City Park of Prizren - a park offering recreation, entertainment and relaxation for all citizens regardless of gender, age, ability and economic situation.

The derived design concepts emerged during the discussions and presentations of work groups' findings are as following:

Connecting the green areas. This design concept is concerned with the connection of the city park and university campus with the aim of creating a larger green area in the city. Currently, the university campus park is surrounded by a metal fence as is the city park. And the street passing between these two areas lacks vitality.

Making people walk, bike through and stop in this area, requires removing fences at both sides of the road, positioning park seating facing the street; adding bike lanes, etc. A shared space concept is proposed for the area between the campus and the park, where the sidewalks would be leveled with the road and a $30 \mathrm{~km} / \mathrm{h}$ speed limit should be enforced for car traffic.

Barrier-free park. This design concept is concerned with improving the accessibility of the streets leading to the park and of walking trails and paths within the park (Fig. 4). Improvements of sidewalks, apart from repairing the damaged surfaces, lowering the curbs and adding tactile strips for the blind, should comprise eliminating obstacles such as parked cars and displayed goods from shops. Both these actions require managerial effort from local government as well. Park trails require tactile strips for the blind; decreasing the steep slopes and adding assistive fencing on the moderately inclined ones, etc. With these elements, unrestricted circulation throughout the park for all citizens is aimed.

A park for all - This design concept aims to provide opportunities for individual and group relaxation, leisure and sports. A distribution of various sports and leisure activities for a greater variety of citizens is proposed. The active and noisy areas are to accommodate group activities for all ages and abilities set on the sunny side of the park. The green areas provide tranquility for the elderly and the ones requiring relaxation under the shade of trees. The fitness area and design of children's playgrounds suggests utilization of all the equipment by all adult and children regardless of their ability.

\section{Conclusion}

Making the public space more vigorous and inviting to a diversity of users implies making a serious effort in eliminating many barriers that hinder its usage. In this 
respect, the paper argues that it is important to have the voice of the needy included at equal stance with other citizens in the decision-making process.

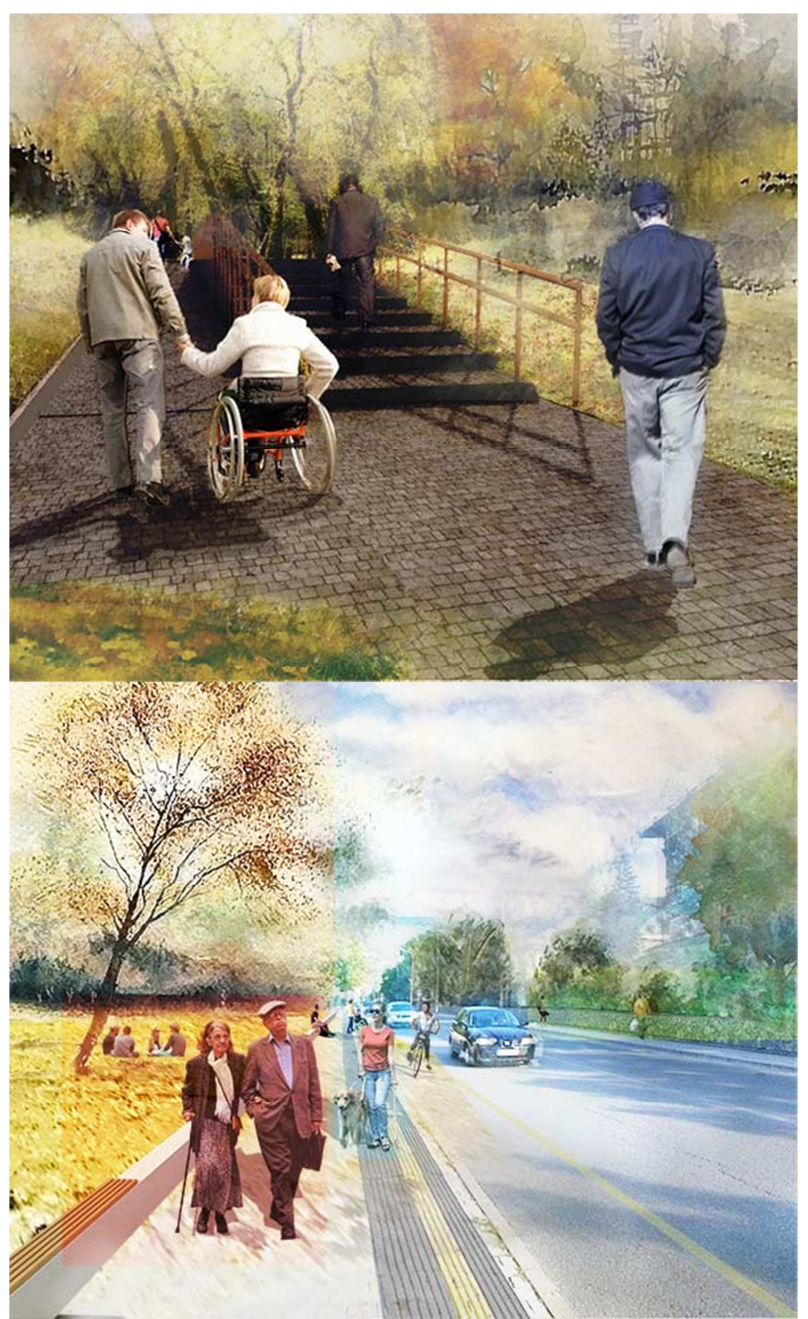

Fig. 4. Vision images of barrier-free park

(Illustrations (C) R. Basha, E. Bajrami, Dh. Avdiu)

As the model of participatory visioning workshop discussed here suggests, having the basic requirements for an increased accessibility of the deprived ones as is the case of people with impaired mobility set at the forefront, it does not only improve technical aspects of infrastructure but it bolsters the quality of public life for everyone.

The workshop's output data which are the three visions produced with the community of PwD and the elderly encapsulate qualities of accessibility, safety, 
security, vitality, diversity and democracy for all regardless of age, sex, ability and financial situation.

The participatory workshop as an applied methodology of gathering information, identifying requirements, setting design criteria, establishing qualities of public life, in the case described here is seen appropriate relevant to the involved participants.

A further research is required towards refining the tools of communication with different groups of disability, as the case study discussed here focuses mainly in restricted group of wheelchair-users and people with impaired vision.

\section{Acknowledgments}

This paper, with the aim of developing its scientific argument discusses the Visioning Workshop City Park of Prizren for All, in which the author of this paper has been engaged in the quality of the architect in charge of developing the visioning workshop's methodology, facilitating participatory process and producing the design and visions for an accessible park. The visioning workshop has been undertaken as part of the project 'Prizren, a City without Barriers' implemented by local NonGovernmental Organizations Emancipimi Civil Ma Ndryshe (EC Ma Ndryshe) and Organizata e Personave me Distrofi Muskulare të Kosovës (OPDMK), sponsored by United States Agency for International Development (USAID) within the E4E program and monitored by Non-Governmental Organization Advocacy Training and Resource Center (ATRC). Special thanks go to students of architecture Dhurata and Egzon whose support and work within the project is invaluable.

\section{References}

[1] Sugranyes A., Mathivet Ch. (Eds.) Cities for all: Proposals and experiences towards the right to the city, Habitat International Coalition, HIC, 2010, http://www.citiesalliance.org/ sites/citiesalliance.org/files/Cities_For_All_ENG.pdf (last visited 25 December 2017).

[2] Portschy Sz. Design partnerships between communities engaged architecture and academic education programs, Pollack Periodica, Vol. 10, No. 1, 2015, pp. 173-180.

[3] Administrative Instruction on Accessibility of Buildings, No. 33/2007, (in Albanian), https://gzk.rks-gov.net/ActDetail. aspx?ActID=7480, (last visited 25 December 2017).

[4] Basha R. Disability and public space - Case studies of Prishtina and Prizren, International Journal of Contemporary Architecture 'The New ARCH' Vol. 2, No. 3, 2015, pp. 54-66.

[5] Legislation on Spatial Planning of Republic of Kosovo, No. 04/L-174 (in Albanian), https://gzk.rks-gov.net/ActDetail.aspx?ActID=8865, (last visited 25 December 2017).

[6] Basha R. How to design a barrier-free city, (in Albanian), Online Report, NGO EC Ma Ndryshe, 2016, http://www.ecmandryshe.org/repository/docs/161123204838_Ecmandryshe manuali nov2016 alb final.pdf, (last visited 25 December 2017).

[7] Carr S., Francis M., Rivlin L., Stone A. Public space, Cambridge University Press, 1995.

[8] Szkordilisz F. Mitigation of urban heat islands by green spaces, Pollack Periodica, Vol. 9, No. 1, 2014, pp. 91-100.

[9] Ojeda-Revah L., Bojorquez I., Osuna J. C. How the legal framework for urban parks design affects user satisfaction in a Latin American city, Cities, Vol. 69, 2017, pp. 12-19.

[10] Greed C. Inclusive urban design: Public toilets, Architectural Press, 2003. 
[11] Portschy Sz. Community participation in sustainable urban growth, Case study of Almere, The Netherlands, Pollack Periodica, Vol. 11, No. 1, 2016, pp. 145-156.

[12] Purcell M. Citizenship and the right to the global city: Reimagining the capitalist world order, International Journal of Urban and Regional Research, Vol. 27, No. 3, 2003, pp. 564-590.

[13] Mueller J., Lu H., Chirkin A., Klein B., Scmitt G. Citizen design science: a strategy for crowd-creative urban design, Cities, Vol. 72, Part A, 2018, pp. 181-188.

[14] Ellin N. Good urbanism: Six steps to creating prosperous places (Metropolitan Planning + Design), Island Press, Kindle Edition, 2012.

[15] Imrie, R., Hall, R., Inclusive design: Designing and developing accessible environments, Taylor \& Francis, 2001.

[16] Binder T., Brandt E., Ehn P., Halse J. Democratic design experiments: between parliament and laboratory, International Journal of CoCreation in Design and the Arts, Vol. 11, No. 3-4, 2015, pp. 152-165.

[17] Basha R. Report of visioning workshop for the city park of Prizren for all (in Albanian), Online report of Visioning Workshop 'City park for all', NGO EC Ma Ndryshe, 2016, http://www.ecmandryshe.org/repository/docs/161208123218 RAPORTI_I_PUNETORISE SE_VIZIONIMIT_PARKU_I_PRIZRENIT_RBASHA.pdf, (last visited 8 February 2018).

[18] Boys J. Doing disability differently: An alternative handbook on architecture, disability and designing for everyday life, Routledge, 2014.

[19] Municipal directorate of public facilities in Prizren, (in Albanian) https://kk.rksgov.net/prizren/News/Drejtoria-e-Sherbimeve-Publike-ne-komunen-tone-esh.aspx, (last visited 25 December 2017). 